\title{
Electrical Simulation of Organic Solar Cell at Different Charge Carrier Mobility
}

\author{
Narender Singh ${ }^{*}$, Ashish Chaudhary ${ }^{*}$, Sandeep Saxena ${ }^{\#}$, Manish Saxena ${ }^{\$} \&$ \\ Nikhil Rastogi* \\ "Department of Physics, School of Sciences, IFTM University, Moradabad, UP, India. \\ ${ }^{\#}$ Department of Physics, Bareilly College, Bareilly, UP, India. \\ ${ }^{\$}$ Department of Physics, Moradabad Institute of Technology, Moradabad, UP, India.
}

\begin{abstract}
The organic photovoltaic device has been electrically simulated by GPVDM software model at different charge carrier mobility. Organic bulk heterojunction solar cell consists of the mixture of electron donor (P3HT) and electron acceptor (PCBM) materials as active layer, ITO (indium tin oxide) is a transparent electrode, PEDOT: PSS is electron blocking layer and Al is a back electrode. In this study the electrical simulation has been done at different charge mobility $0.5 \times 10^{-4} \mathrm{~m}^{2} \mathrm{v}^{-1} \mathrm{~s}^{-1}, 0.5 \times 10^{-5} \mathrm{~m}^{2} \mathrm{v}^{-1} \mathrm{~s}^{-1}, 0.5 \times 10^{-6} \mathrm{~m}^{2} v^{-1} \mathrm{~s}^{-1}$ and $0.5 \times 10^{-7} \mathrm{~m}^{2} v^{-1} \mathrm{~s}^{-1}$ respectively. It is observed that $\mathrm{J}$-V characteristics are affected by charge carrier mobility and it is concluded that the best $J$-V characteristic is obtained at $0.5 \times 10^{-6} \mathrm{~m}^{2} v^{-1} \mathrm{~s}^{-1}$ carrier mobility.
\end{abstract}

Keywords: GPVDM software, Bulk heterojunction, Organic solar cell, charge carrier mobility

\section{Introduction}

Photovoltaic cell is the electronic device that converts sun light directly into the electrical energy. Now day's organic photovoltaic (OPV) devices attract more and more interest for researchers. Organic semiconductors have proved to be quite different material for organic solar cell, as these have applications for thin film structure, room temperature processing, flexible substrate, light weight, and low cost fabrication [1]. Organic solar cells offer considerable promise for use in new solar energy technology, due to their flexible material properties and low-cost manufacture [2]. Organic solar cells based on a bulk heterojunction (BHJ) composites of conjugate polymers $\mathrm{P} 3 \mathrm{HT}$ (poly 3-hexylthiophene) and PCBM (phynyl- $\mathrm{C}_{70}$ butyric acid methyl ester)that allow the maximum absorption of light and have been reported among the highest performing material for researchers investigation and studies [3-8] for improving their power conversion efficiencies. In organic solar cell, bulk heterojunction (BHJ) formed by an interpenetrating of a conjugate polymer and electron accepting molecules constitute a very promising route towards cheap and flexible solar cells [9-10] as recently exhibited in progress of automated roll-to-roll processing and solar cell stability [11-12]. The energy conversion efficiency of bulk heterojunction solar cell based on $\mathrm{P} 3 \mathrm{HT}$ and $\mathrm{PC}_{70} \mathrm{BM}$ organic materials is nearly $6 \%$ and $6.1 \%$ efficiency achieved when using PCDTBT and $\mathrm{PC}_{70} \mathrm{BM}$ organic materials. The advantage of the $\mathrm{BHJ}$ structure is that the maximum photons are absorbed by the active layer and most of the generated excitons(electron-hole pair) reach a nearby donor - acceptor interface where they dissociate into free charge carriers (electrons and holes).These efficient excitons harvesting leads to higher power conversion efficiencies for BHJ solar cells. In BHJ solar cell the mobility is identified as one of the key factor, which affects $\mathrm{j}$-v characteristics of organic photovoltaic devices through reduction of the efficiency of solar cell and fill factor [14]. The overall result of electronic transport mechanisms is recognized to have a good effect when thin active layer films are used to increase foe the harvesting of light [15]. While thin films of the active materials are able to exhibit almost conversion of absorbed photon into collected charge carriers [16]. For organic solar cell, in case of blends, it was assumed that the electron and hole mobility should be used. It has been observed that the charge carriers mainly governed by the recombination process in the blends, since the fastest charge carriers cannot cross the interface due to the energy between the donor and acceptor, it must wait for the slowest carriers in order to recombine [17]. The organic solar cell has two competing process, extraction and recombination of the charge carriers, both process are conducted by the mobility of the charge carrier. As increase charge carrier mobility would have a positive effect on transport, facilitating extraction, but on other hand it increases the bimolecular recombination. In this research article, we study the dependence of solar cell $\mathrm{j}$-v characteristics on charge carrier mobility. We found electrical simulation of bulk heterojunction (BHJ) solar cell using GPVDM (General purpose photovoltaic device model) software at different charge mobility.

\section{Bulk heterojunction:}

In an organic solar cell, Bulk heterojunction is a mixture of interpenetrating of electron donor (P3HT) and electron acceptor conjugated molecules (PCBM) that allows light absorption, generation of excitons, 
excitons splitting at donor-acceptor interface and efficiently transportation of positive and negative charges to opposite electrodes. Bulk heterojunction are mostly governed by forming a containing the two semiconductor organic materials, casting and then allowing separating the two phases, usually with the help of annealing process. The two conjugate organic materials will self assembled into an interpenetrating system connecting the two electrodes [18].The structure of bulk heterojunction ITO/PEDOT:PSS/ P3HT:PCBM/ Al solar cell is shown in figure-1 $(\mathrm{a}, \mathrm{b})$.

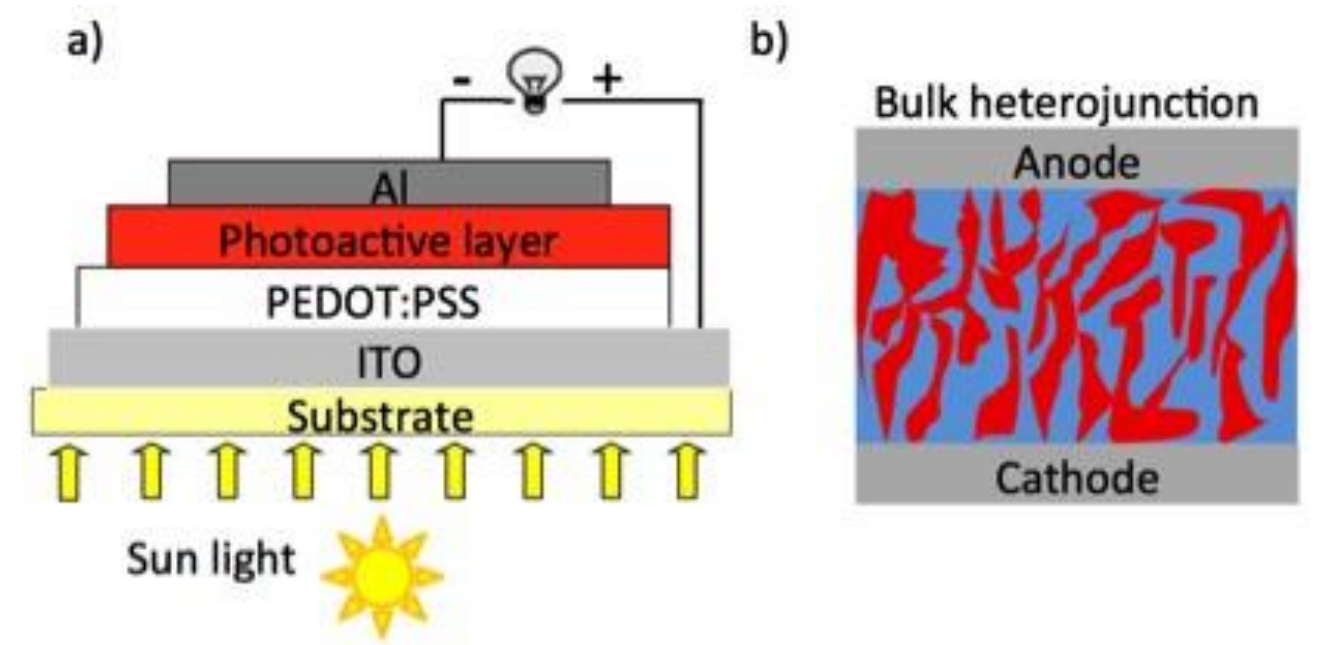

Figure- 1(a, b) Bulk Heterojunction solar cell

In ITO/PEDOT: PSS/P3HT: PCBM/Al bulk heterojunction solar cells, the active layer material P3HT (3-hexyl thiophene) is a good electron donor that effectively transports positive holes and PCBM ([6, 6]-phenyl $\mathrm{C}_{61}$-butyric acid methyl ester) is a good electron acceptor. It efficaciously transports electrons from molecule to molecule. The Indium Tin Oxide (ITO) film is used as a transparent front electrode. Since, it has high transmittance in visible region and ability of conduction. PEDOT: PSS or poly (3, 4-ethylenedioxythiophene) poly (styrenesulfonate) is an electron blocking layer. PDOT: PSS may be used as buffer layers between the electrodes and active layer to block the electron and hole transfer in the wrong direction.

\section{Electrical Simulation:}

Bulk heterojunction solar cell ITO/PEDOT: PSS/P3HT: PCBM/Al is electrically simulated by the GPVDM software at different charge carrier's mobility. GPVDM software is specifically developed for the simulation of bulk heterojunction solar cells, which is based on the P3HT: PCBM materials. The model contains two types of properties like as electrical and optical; permitting both current- voltage characteristics to be simulated as well as optical properties [19-20]. The electrical simulation only covers the active layer of the device. In this electrical model, there are two types charge carriers like as electrons (holes), free electrons (holes) and trapped electrons (holes). The free electrons (holes) have a finite mobility of $\mu_{e}^{\circ}\left(\mu_{h}^{\circ}\right)$ and trapped electrons (holes) cannot move at all and have a mobility of zero. To find the average mobility of the charge, the ratio of free to trapped carriers will multiply by the free carrier mobility then we found the equation

$\mu_{e}(n)=\frac{\mu_{e}^{o} n_{\text {free }}}{n_{\text {fres }}+n_{\text {trap }}}$

Thus if all the charge carriers were free the average mobility would be $\mu_{e}^{\circ}$ and if all charge carriers were trapped the average mobility would be zero. It should be noted that only $\mu_{e}^{o} \mu_{h}^{o}$ are used in the model for computation and using $\mu_{\mathrm{e}}(\mathrm{n})$ is an output parameter.

The electrical simulation window is shown in figure- 2 . 


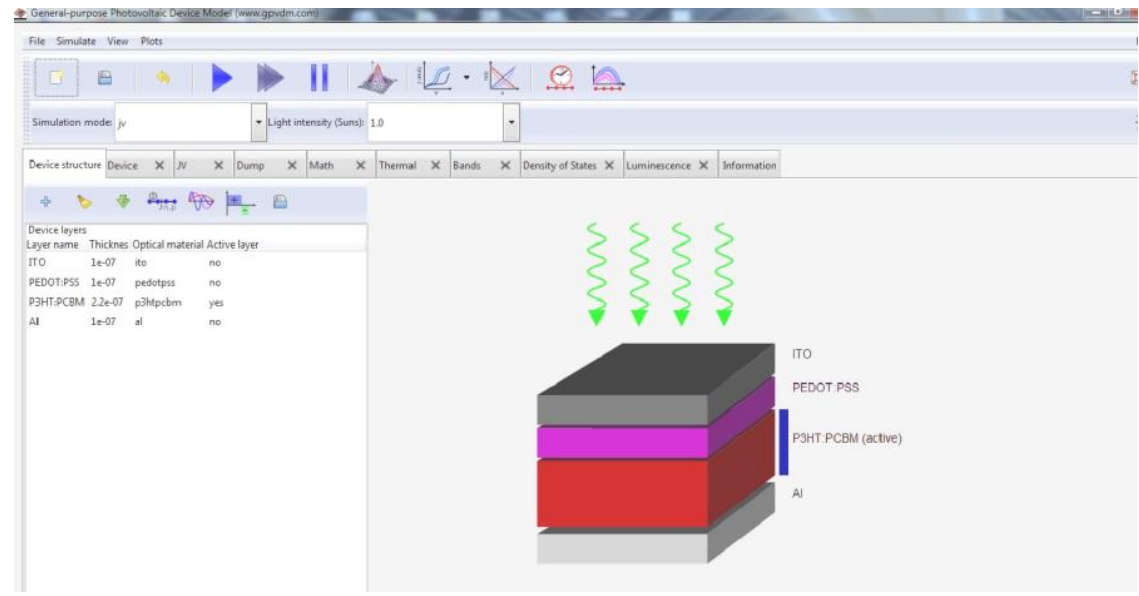

Figure- 2 GPVDM, Electrical Simulation window

\section{Result And Discussion}

In this research paper, we found the dependence $\mathrm{j}$-v characteristics of solar cell at different charge mobility. In BHJ solar cell, in which the blend is treated as one effective medium with an effective band- gap given by LUMO (lowest unoccupied molecular orbit) of acceptor and HOMO (highest occupied molecular orbit) of donor [21]. We concluded that the best solar cell efficiencies are achieved in mobility range $10^{-6}$ to $10^{-4} \mathrm{~m}^{2} \mathrm{v}^{-1} \mathrm{~s}^{-1}$. For higher mobility, the efficient extraction of carriers strongly reduces the steady states charge carrier density leading to a reduction of the open-circuit voltage. The $\mathrm{j}-\mathrm{v}$ characteristics curves at different electron and hole mobilities are shown in the figure- $3 \& 4$.

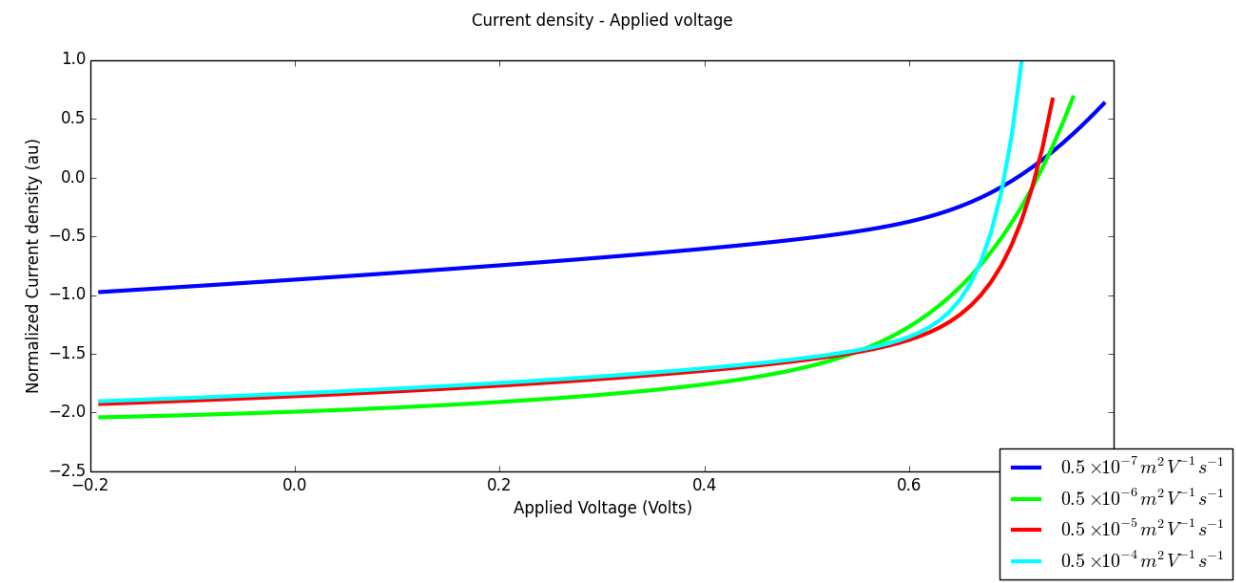

Figure- $3 \mathrm{~J}-\mathrm{V}$ Characteristics at different electron mobility $0.5 \times 10^{-4}, 0.5 \times 10^{-5,} 0.5 \times 10^{-6}, 0.5 \times 10^{-7}$

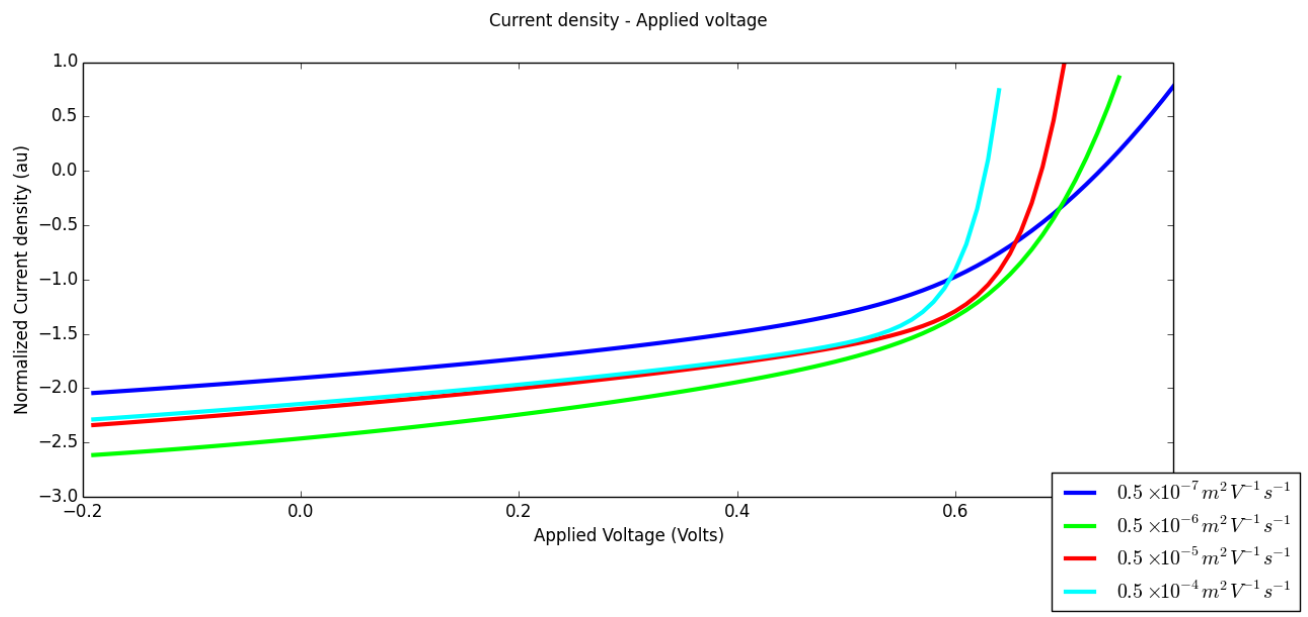

Figure- $4 \mathrm{~J}-\mathrm{V}$ Characteristics at different hole mobility $0.5 \times 10^{-4}, 0.5 \times 10^{-5}, 0.5 \times 10^{-6}, 0.5 \times 10^{-7}$ 


\section{Conclusion}

In this research work, the electrical simulation of the bulk heterojunction (P3HT: PCBM) organic solar cell has done. The J-V characteristics curve of organic solar cell varies with mobility of charge carriers. In this study, we obtained the maximum short circuit current at electron and hole mobility $0.5 \times 10^{-6} \mathrm{~m}^{2} \mathrm{v}^{-1} \mathrm{~s}^{-1}$ due to maximum dissociation probability. If the mobility increased or decreased from $0.5 \times 10^{-6} \mathrm{~m}^{2} \mathrm{v}^{-1} \mathrm{~s}^{-1}$, the dissociation probability decrease and the short circuit current also decrease. The optimum efficiency of organic solar cell is obtained at $0.5 \times 10^{-6} \mathrm{~m}^{2} \mathrm{v}^{-1} \mathrm{~s}^{-1}$ charge mobility. It is concluded that the $\mathrm{j}-\mathrm{v}$ characteristics of organic solar cell affected by the mobility of the charge carrier.

\section{Acknowledgement}

The authors sincerely thank the honorable Vice Chancellor of IFTM University, Moradabad for his support and encouragement to complete this research work. The authors also wish to acknowledge research group of Physics Lab, School of Sciences, IFTM University, Moradabad for their constant help during the work.

\section{Reference}

[1]. C. J. Brabec, G. Zerza, G. Cerullo, S. De Silvestri, S. Luzzati, J. C. Hummelen, S. Sariciftci, Tracing photo induced electron transfer process in conjugated polymer/fullerene bulk heterojunctions in real time, Chemical Physics Letters 340 (2001), 232.

[2]. Tang, CW.; Albrecht, AC. "Photovoltaic effects of metal-chlorophyll-a-metal sandwich cells"J.Chem.Phys.62 No.6 (1975) pp. 2139-2149.

[3]. S.C Jain, M. Willander and V. Kumar, Conducting organic material and devices (Academic, San Diego, (2007).

[4]. F. Padinger, R. S. Ritterberger, and N. S. Sariciftci, Effects of postproduction treatment on plastic solar cells, Adv. Funct. Mater. 13 (2003) 85-88.

[5]. Y. Kim, S. Cook, S. M. Tuladhar, S. A. Choulis, J. Nelson, J. R. Durrant, D. D. C. Bradley, M. Giles, I. McCulloch, C. S. Ha, and M. Ree, A strong regioregularity effect in self-organizing conjugated polymer films and high-efficiency polythiophene:fullerene solar cells, Nat. Mater. 5 (2006) 197-203.

[6]. N. Rastogi , N. Singh , M. Saxena , International Journal of Innovative Research in Science, Engineering and Technology Vol. 2, 12,2013

[7]. J. A. Hauch, P. Schilinsky, S. A. Choulis, R. Childers, M. Biele, and C. J. Brabec, Flexible organic P3HT:PCBM bulkheterojunction modules with more than 1 year outdoor lifetime, Sol. Energy Mater. Sol. Cells 92 (2008) 727-731.

[8]. C.J. Brabec, N.S. Sariciftci, C. Hummelen, Plastic Solar Cells, Advanced Materials 11 (2001) 15-26.

[9]. S.H. Park, A. Roy, S. Beaupre', S. Cho, N. Coates, J.S. Moon, D. Moses, M. Leclerc, K. Lee, A.J. Heeger, Bulk heterojunction solar cells with internal quantum efficiency approaching 100\%, Nature Photonics 3 (2009) 297-302.

[10]. Mayer, A.C.; Scully, S.R.; Hardin, B.E.; Rowell, M.W.; McGehee, M.D. "Polymer-based solar cells". Materials today, Vol.10, No.11, Nov. (2007) pp.28-33

[11]. F.C. Krebs, et al., A round robin study of flexible large-area roll-to-roll processed polymer solar cell modules, Solar Energy Material and Solar Cells 93 (2009) 1968-1977

[12]. N. Rastogi, N. Singh, Electrical simulation of organic solar cell at different series resistances and different temperature IOSR-JAP 8 (2016) 54-57.

[13]. F.C. Krebs, S.A. Gevorgyan, J. Alstrup, A roll-to-roll process to flexible polymer solar cells: model studies, manufacture and operational stability studies, Journal of Materials Chemistry 19 (2009) 5442-5451

[14]. S.R. Cowan, N. Banerji, W.L. Leong, A.J. Heeger, Charge formation, recombination, and sweep-out dynamics in organic solar cells, Adv.Funct. Mater. 22 (2012) 1116-1128

[15]. S.H. Park, A. Roy, S. Beaupré, S. Cho, N. Coates, J.S. Moon, D. Moses, M. Leclerc, K. Lee, A.J. Heeger, Bulk heterojunction solar cells with internal quantum efficiency approaching 100\%, Nat. Photonics 3(2009) 297-30.

[16]. G. Horowitz , R. Hajlaoui , D. Fichou , A. El Kassmi , J. Appl. Phys. 1999 , 85, 3202.

[17]. R. J. Kline, M. D. McGehee, E. N. Kadnikova , J. S. Liu , J. M. J. Frechet , Adv. Mater.2003, $15,1519$.

[18]. T. Zhan, X. Shi, Y. Dai, X. Liu, and J. Zi. Journal of Physics: Condensed Matter, 2521 ( 2013) 215301

[19]. N. Singh, A. Chaudhary, N. Rastogi, Simulation of Organic Solar Cell at Different Active Layer Thickness, International Journal of Material Science, 5(1):22-26 · January 2015 Volume 5, Issue 1, Pages 22-26, (2015)

[20]. L. J. A. Koster, E. C. P. Smits, V. D. Mihailetchi, and P. W. M. Blom, Phys. Rev. B 72, 085205 (2005)

[21]. L. J. A. Koster, V. D. Mihailetchi, and P. W. M. Blom, Appl. Phys. Lett. 88, 052104 (2006). 